\title{
肝細胞癌の動脈塞栓療法に用いる塩酸エピルビシン封入 $\mathrm{w} / \mathrm{o} / \mathrm{w}$ 型エマルションの設計と in vivo 評価
}

\author{
竹内洋文・竹内夕紀子・日野知証・山本浩充・川島嘉明*1), \\ 中野 哲・山崎 太・熊田卓・佐々 敏*2)
}

Formulation and in vivo evaluation of $w / 0 / w$ emulsion encapsulating Epirubicin hydrochloride for the transcatheter arterial embolization therapy for hepatocellular carcinoma

We developed a novel $\mathrm{w} / \mathrm{o} / \mathrm{w}$ emulsion formula. tion containing medium-chain triglyceride(MCT) as an oily phase and Iomeron 300 as an aqueous phase with functions of embolizing and sustaining drug-release in trans-catheter arterial embolization(TAE) therapy for hepatocellular carcinoma. The various formulations with various kinds of surfactants were applied to the MCT w/o/w emulsion to improve its stability. The most stable w/o/ $\mathrm{w}$ emulsion was obtained when the mixture of $\mathrm{HCO}-10$ and $\mathrm{CO}-3(1: 1)$ of $3 \%$ in oily phase and $\mathrm{HCO}-60$ of $5 \%$ in aqueous phase were formulated. The stability of emulsion was also evaluated by a drug release test with Spin-Biodialyser ${ }^{\mathrm{TM}}$ Doublesided for the emulsions encapsulating epirubicin hydrochloride(EPI), doxorubicin hydrochloride (DOX) or Evans blue in an inner aqueous phase. The drug release profiles suggested the sustained drug release property of the emulsions. When normal rats were treated with the hepatic arterial injection of the MCT w/o/w emulsion encapsulating EPI, there was non dysfunction trans aminase of GOT and GPT in normal liver. The increased drug retention in liver after the arterial administration of EPI in a w/o/w emulsion form in rats bearing a hepatic tumor revealed the usefulness of this device for the drug targeting to the hepatic tumor.

Hirofumi Takeuchi - Yukiko Takeuchi •

Tomoaki Hino $\cdot$ Hiromitsu Yamamoto

Yoshiaki Kawashima*1),

Satoshi Nakano $\cdot$ Futoshi Yamazaki .

*1) Department of Physical Pharmaceutics, Gifu Pharma. ceutical University 伎草薬科大学堪剂学教公

*2) Ogaki Municipal Hospital 大垣市民病院

Offprint requests to : Yoshiaki Kawashima, $\mathrm{Ph} . \mathrm{D}$., Department of Physical Pharmaceutics, Gifu Pharmaceutical University, 5-6-1 Mitahora-higashi, Gifu 5028585
Takashi Kumada $\cdot$ Toshi Sassa*2) key words : w/o/w emulsion, Epirubicin hydrochloride, transcatheter arterial embolization, hepatocellular carcinoma

近年, 肝細胞癌の治療は, 画像診断の向上と新 しい治療法の開発により，著しい進歩を遂げてき ている、しかしながら，いまだ肝細胞癌に対する 治療方針のコンセンサスが形成されているとは言 い難いのが現状であり, 肝切除, 経カテーテル動 脈塞栓療法(TAE), 経皮的エ夕ノール注入療法や 肝移植,さらにはこれらと放射線療法, 化学療法 などを組み合わせた集学的治療が行われている11.

TAEの一種として, 選択的腫煌蓄積性を有す る油性造影剂であるリピオドール(LPD) と, 抗癌 剤をエマルション化した液体を腫場全体に充埧さ せる Lp-TAE が比較的多くの施設で行われてい る、筆者らの研究室では，塞栓と同時に薬物を効 果的に肝内に滞留させることを目的としたデバイ スとして, w/o/w 型エマルションを適用する検討 を行ってきた。これまでに，術中においても簡便 かつ無菌的調製が可能である二段階パンピング法 を使用し, 多量の薬物を封入, 保持できる抗癌剤 封入リピオドール $\mathrm{w} / \mathrm{o} / \mathrm{w}$ 型エマルションを開発 し，その安全性と肝臟中での薬物滞留性について 知見を得ている2-4). しかし近年, リピオドールに ついては，TAE 使用例で胆管障害，胃・十二指腸 潰瘍や脳梗塞，肺梗塞などの合併症が報告される ようになった ${ }^{5,6)}$. また, 医療現場からは, TAE 後, 長期にわたつて肝臟内に停滞し，かつ造影能を有 するため, 予後の肝臟の造影検查に支障をきたす との報告もある. 
本研究では，これらの欠点を改善することを目 的とし, LPDに代わる油性キャリアとして, 造影 能を持たずに LPD と同様の腫瘍蓄積性が報告さ れている ${ }^{7,8)}$ 中鎖脂肪酸トリグリセリド (MCT) と, 水溶性造影剤を用いた MCT w/o/w 型エマル ションの設計を試みた。そしてその安全性, なら びに肝臟中での薬物滞留性についてラットを用 い, in vivo で評価した。 また肝臓癌モデルラット を用いた評価も同様に行った。

\section{試料と方法}

\section{(1) 試 料}

エマルションの油相に中鎖脂肪酸トリグリセリ ド(トリエスターF-810 $)$, 水相に水溶性造影剤 のイオメロン $300^{\ominus}$ (エーザイ), 薬物として抗腫瘍 抗生物質, 塩酸エピルピシン(ファルモルビシン 注 ${ }^{\circledR}$, 協和発酵)，塩酸ドキソルビシン(原末, 協和 発酵より供与), エバンスプルー(ナカライテスク) を用いた。

界面活性剤として，ポリオキシエチレン硬化ヒ マシ油 60(HCO-60), ポリオキシエチレン硬化ヒ マシ油 10(HCO-10), ポリオキシエチレンヒマシ 油 3(CO-3) (以上, 日本サーファクタント工業 (梸)，ポリオキシエチレンヒマシ油(Cremophor ELP), ポリオキシエチレンヒドロキシステア レート (Solutol HS 15), ステアリン酸マクロゴー ル (Cremophor S 9) (以上, BASF 社), Tween 20, Tween 80, Span 80, Span 85 (以上, キシダ化学 (粕)を用いた。

また, ラット肝動脈投与後の血中 GOT, GPT 值の測定には, GOT-UV テストワコー, GPTUV テストワコー(以上, 和光純薬工業(侏)を用い た.ラット開腹手術における麻酔薬としてはペン トバルビタールナトリウム(ネンブタール注, ダイ ナボット(侏)を使用した。

（2）パンピング法によるエマルションの調製 エマルションの調製は，水相と油相をそれぞれ 2 本のシリンジ(テルモシリンジ, テルモ)に充填 し，三方活栓(トップ化成)で接続してシリンジ内 容物を往復させる方法(パンピング法)により行っ た. w/o 型エマルションの調製では, パンピング

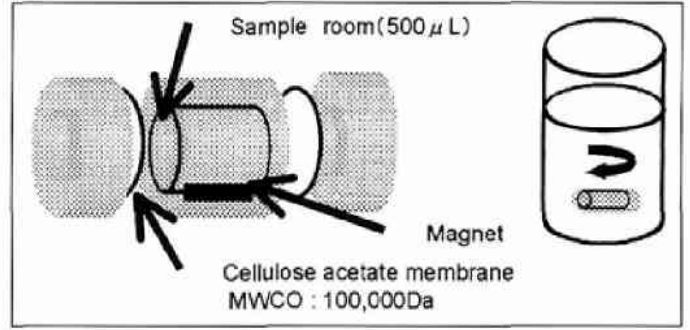

図 1 In vitro drug release assembly

は速度 $30 \mathrm{spm}, 40$ 回 (20 往復) とした。 w/o/w 型 エマルションの調製では, 1 次乳化は速度 30 $\mathrm{spm}, 40$ 回 (20 往復) 2 次乳化は速度 $6 \mathrm{spm}, 20$ 回 (10 往復)で行った.

\section{（3）エマルションの安定性評価}

調製したエマルションを室温下放置し, 調製直 後から経時的に肉眼で観察し, 分離の認められな かったエマルションを“安定である”とした。

\section{(4) 薬物溶出試験}

調製した $\mathrm{w} / \mathrm{o} / \mathrm{w}$ 型エマルションを小型透析セ ル (Spin-Biodialyser ${ }^{\mathrm{TM}}$ Double-sided, sialomed 社）を用いた溶出試験により評価した. モデル薬物 として, 塩酸エピルピシン, 塩酸ドキソルピシン, エパンスブルーを用い，内水相における薬物濃度 は $5 \mathrm{mg} / \mathrm{ml}$ とした. 方法は, 調製した塩酸エピル ビシン封入 MCT w/o/w 型エマルションを, 図 1 に示す小型透析セルのサンプルルームに満たし $(500 \mu 1), \quad \mathrm{MWCO}$ が $100,000 \mathrm{Da}$ のメンブレンで 挟み, 生理食塩水 $300 \mathrm{ml}\left(37^{\circ} \mathrm{C}\right)$ で 24 時間透析を 行い, 経時的に試験液 $0.5 \mathrm{ml}$ を採取し, 蛍光強度 の測定より試験液中の塩酸エピルビシンを定量 し，塩酸エピルピシンの放出率を(1)式，(2)式よ り算出した.

$$
\mathrm{Mi}=\left(\frac{(300+\mathrm{V}) \mathrm{Ci}}{100}+0.5 \sum_{\mathrm{k}=1}^{\mathrm{i}-1} \frac{\mathrm{Ck}}{100}\right) \times 100
$$

$\mathrm{Mi}$ ：溶出量 $(\mathrm{g}), \mathrm{V}$ : 透析セル内の水溶液量, $\mathrm{Ci}$ ： 各サンプルの薬物濃度 $(\%)$

$$
\mathrm{DR}(\%)=\frac{\mathrm{Mi}}{\mathrm{M}} \times 100
$$

$\mathrm{M}$ : 透析チューブ内の総薬物量 
表 1 Effect of the type and concentration of surfactant added in oil phase on the stability of w/o emulsion*

\begin{tabular}{ccccccc}
\hline surfactant & conc. (w/v) & type & $5 \mathrm{~min}$ & $1 \mathrm{hr}$ & $2 \mathrm{hr}$ & $4 \mathrm{hr}$ \\
\hline HCO-10 & $5 \%$ & w/o & - & - & - & + \\
CO-3 & $5 \%$ & w/o & - & - & - & - \\
Cremophor S9 & $5 \%$ & w/o & - & - & - & - \\
Solutol HS 15 & $5 \%$ & w/o & - & - & - & - \\
\hline HCO-10 & $3 \%$ & w/o & - & + & + & + \\
CO-3 & $3 \%$ & w/o & - & - & \pm & \pm \\
Cremophor S9 & $3 \%$ & w/o & - & - & - & - \\
Solutol HS 15 & $3 \%$ & w/o & - & - & - & - \\
HCO-10: CO-3=1:1 & $3 \%$ & w/o & - & - & - & - \\
\hline
\end{tabular}

- : stable, $\pm:$ incompletely separated, + : completely separated, "geration aqueous phase $:$ oil phase $=1.0: 2.0$

\section{(5) In vivo 評価}

\section{(1) 動 物}

日本 SLC 社の SD 系雄性ラット (9 10 週齢) を用いた. 肝睵癌モデルラットは, SD 采雄性ラッ 卜 (7 週齢)へ同系腫瘍である MRMT- 1 細胞を $1 \times 10^{6}$ 個肝臓㲹注入移植して作成し, 移植 10 日後 のものを使用した.

\section{(2) 投与法}

薬物溶液㧍よび各エマルションを左大胃動脈よ り血液にのせ，肝動脈へ投与した，まず，ペント パルビタールナトリウムの腹腔内投与による麻醉 下で，ラット腹部の正中線に沿って開腹し，肝動 脈, 胃十二指腸動脈を露出させる, 試験液が流入 しないように胃十二指腸動脈および脾動脈をク リップで結禁し，左胃動脈に挿入したカテーテル を通じて注入し，その後血流を再開させるために クリップを外した。 なお, 投与後 5 分後に, 肝動 脈は縫合系で結紮した。

(3) ラット正常肝への影響

薬物溶液拉よび各エマルション投与後 1 日, 3 日, 5 日, 7 日後にエーテル麻醉下で䫓静眽より採 血した，採血した血液を邈心分離したのち，得ら れた血清を測定試料に用いた。対照群には生理食 塩水を投与した。試料について GOT, GPT 測定 キット(GOT-UV テストワコー, GPT-UV テス トワコー(和光純薬工業犐)を用い, GOTおよび GPT を測定した。

\section{(4) 体内動態}

EPI 封入 MCT w/o/w 型エマルションを肝動 脈投与後 $0.5,1,2,4,8,24$ 時間後に頻静脈よ り採血し, 血液を遠心分離したのち, 得られた血 清中 EPI 濃度を HPLCを用い定量した。 また, 肝 動脈投与後 1,24 時間後に脱血死させ肝臟を摘出 し, 肝臟内 EPI 濃度も同様に定量した。

\section{(5) 定量方法}

EPI の)定量は, 有機溶媒(トルエン：n-ブタ ノール=1：1)で抽出操作を行ったのち HPLC で 定量した。測定条件は, カラム：Inertsil ODS$2(4.0 \times 10 \mathrm{~mm})$, 移動相 : $0.03 \mathrm{M} \mathrm{NH}_{4} \mathrm{H}_{2} \mathrm{PO}_{4}$ : $\mathrm{MeOH}=3: 7$, カラム温度 : 室温, 流速 $: 0.7 \mathrm{ml}$, 波長：Ex $470 \mathrm{~nm}, \operatorname{Em} 585 \mathrm{~nm}$ とした。

\section{結果と考察}

\section{(1) エマルション処方の検討}

一般に，安定な $\mathrm{w} / \mathrm{o} / \mathrm{w}$ 型エマルションを調製 するためには, 分散相である w/o 型エマルション が安定である必要があると考えられる，当研究室 においてすでに行った，リピオドール $\mathrm{w} / \mathrm{o} / \mathrm{w}$ 型 エマルションの設計においても，このことは確認 されている，そこで今回，MCT w/o/w 型エマル ションを設計するに当たっても，まず w/o 型エマ ルションの安定性を向上させるための処方検討を 行った.

水相：油相の体積比を $1.0: 2.0$ と固定し, 生成 するエマルションの型, 経時安定性を評価した。 
表 2 Effect of the type of surfactants on the stability of MCT w/o/w emulsion*

\begin{tabular}{|c|c|c|c|c|c|c|c|}
\hline Rp No. & $\begin{array}{l}\text { surfactants } \\
\text { inner aqueous phase }\end{array}$ & $\begin{array}{l}\text { conc. } \\
(w / v)\end{array}$ & $\begin{array}{l}\text { surfactants } \\
\text { oil phase }\end{array}$ & $\begin{array}{l}\text { conc. } \\
(w / v)\end{array}$ & $\begin{array}{l}\text { surfactants } \\
\text { outer aqueous phase* }\end{array}$ & $\begin{array}{l}\text { conc. } \\
(w / v)\end{array}$ & type \\
\hline 1 & HCO 60 & $5 \%$ & $\mathrm{HCO}-10+\mathrm{CO}-3$ & $3 \%$ & HCO 60 & $5 \%$ & $w / o / w$ \\
\hline 2 & Cremophor ELP & $5 \%$ & $\mathrm{HCO}-10+\mathrm{CO}-3$ & $3 \%$ & Cremophor ELP & $5 \%$ & o/w \\
\hline 3 & HCO 60 & $5 \%$ & Solutol HS 15 & $3 \%$ & HCO 60 & $5 \%$ & $w / o / w$ \\
\hline 4 & Cremophor ELP & $5 \%$ & Solutol HS 15 & $3 \%$ & Cremophor ELP & $5 \%$ & $w / o / w$ \\
\hline 5 & HCO 60 & $5 \%$ & Cremophor S9 & $3 \%$ & $\mathrm{HCO} 60$ & $5 \%$ & $0 / w$ \\
\hline 6 & Cremophor ELP & $5 \%$ & Cremophor S9 & $3 \%$ & Cremophor ELP & $5 \%$ & $0 / w$ \\
\hline
\end{tabular}

- : stable, + : completely separated

inner aqueous phase $:$ oil phase $:$ outer aqueous phase $=1: 2: 3$

*Iomeron 300 was 2 times diluted with Tris $0.1 \%$ aqueous solution

表1亿示す界面活性剤を用いた場合にはいずれ も, 観察を行った 4 時間まで安定な $\mathrm{w} / 0$ 型エマル ションが得られた，界面活性剤量はできる限り少 ないほうが好ましいことから，その量を減量した ところ, 表に示すように, CO-3, HCO-10 の場合 は不安定化した, この結果より, Cremophor S 9, Solutol HS 15 が本系に最適な界面活性剂である と判断された. また, $\mathrm{CO}-3, \mathrm{HCO}-10$ の場合には, これらを等量混合して用いることにより，同等な 安定性が得られることが判明し, 以降の検討に用 いることとした，なお，他に検討した Span 80, Span 85, PluronicL-101 の場合は, 同様に w/o 型 エマルションが得られるものの, 体積比を 0.5 ： 2.0 としても経時的な安定性が得られず，不適当 として検討からはずした.

安定性の確認されたこれら 3 種の $\mathrm{w} / \mathrm{o}$ 型エマ ルションを用い, 目的の $\mathrm{w} / \mathrm{o} / \mathrm{w}$ 型エマルション の調製を検討した，外水相としては，内水相に用 いたイオメロン 300 を $0.1 \%$ トリス水溶液で 2 倍 希釈したものを用いた。これは，w/o 型エマル ションとの比重差を少なくし, 安定化を図るため である.また $0.1 \%$ トリス水溶液を用いたのは, 非 イオン性水溶性造影剂イオメロン 300 のなかに は, 保存中の $\mathrm{pH}$ 值を安定化させるために, 緩衝剤 であるトリスヒドロキシメチルアミノメタント リス)が $0.1 \%$ 添加されているからである. また， 内水相: 油相: 外水相の組成比は $1: 2: 3$ とし た。これらの条件下で検討した結果を表 2 に示す。 処方 $1 ， 3 ， 4$ では $\mathrm{w} / \mathrm{o} / \mathrm{w}$ 型エマルションを生成 し， 5 分後においてもすべてのエマルションは安

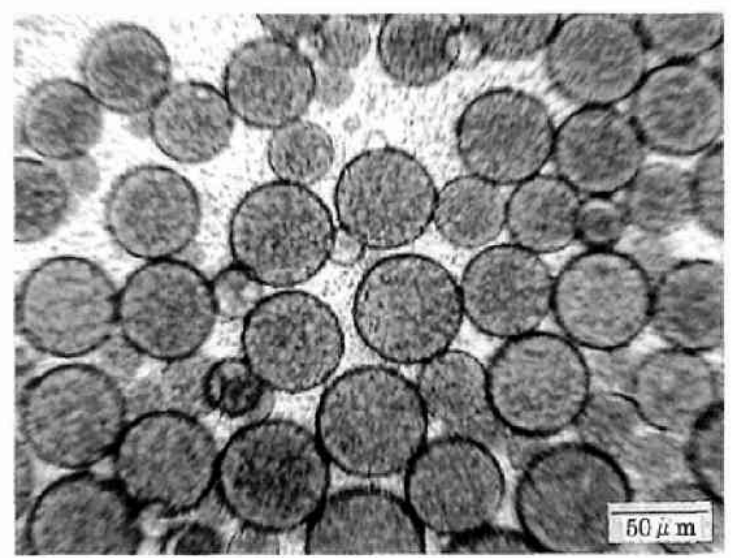

图 2 Optical microphotograph of MCT w/o/w emulsion prepared by the two-step pumping emulsification method

定であった. 生成したエマルションの光学䫓微鏡 写真の一例を図 2 に示す。この写真より，分散す る油滴中に微細な水滴が多数封入された $\mathrm{w} / \mathrm{o} / \mathrm{w}$ 型エマルションであること, その油滴の粒子径は 約 $50 \mu \mathrm{m}$ であることがわかる. これらのエマル ションは, 1 時間放置すると分離がみられたが, 軽 い振量で再分散可能で, w/o/w の型は保たれてい ることが確認できた。

\section{(2) 薬物溶出試験の結果}

w/o/w 型エマルションは熱力学的に安定性が 低く, 薬物を封入することで, その安定性は大き く変化することが䁻念される。また，エマルショ ンの分離の有無のみでは，粒子の合一などを含め たエマルションの系自体の安定性を評価している とは言い難い、そこで, w/o/w 型エマルションに 


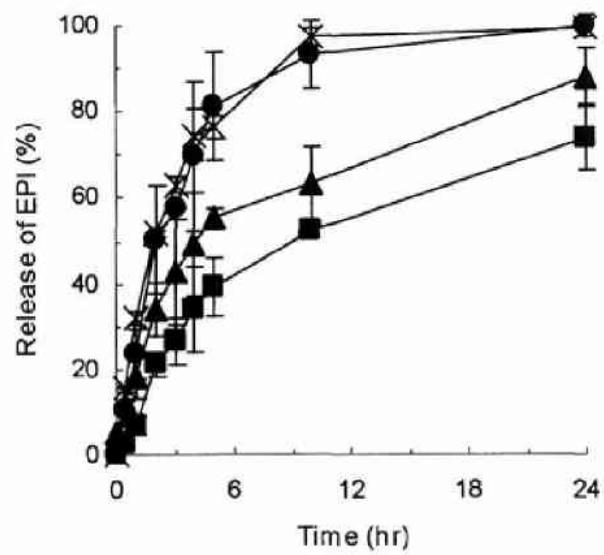

图 3 Effect of drug formulation on the stability of $\mathrm{MCT} \mathrm{w} / \mathrm{o} / \mathrm{w}$ emulsion (mean $\pm \mathrm{SD}, \mathrm{n}=$ 3)

Model drug : Epirubicin hydrochloride(EPI) Conc. of EPI in inner aqueous phase $: 5 \mathrm{mg} / \mathrm{ml}$

- $\mathrm{Rp} 1,-\mathrm{Ap} 3$,

- Rp $4, *$ EPI solution

薬物を封入し, 薬物溶出試験よりその安定性を評 価した.エマルションの溶出試験の方法としては, 透析チューブを用いた透析法が一般的であり，当 研究室でもこれまでは透析チューブを用いた方法 でマルションの溶出試験を行ってきた. しかし, 透析チューブを用いた場合, 浸透圧変化により透 析液がチューブ内に侵入するなどの実験誤差の要 因を含んでおり，改善が望まれる。 そこで今回，

新たに小型透析セル (Spin-Biodialyser ${ }^{\mathrm{TM}}$ Double-sided)の適用を試みた。このセルを用いると 試験中内容積の変化がなく, また少量のサンプル で行える利点がある。

処方番号 $1,3,4$ の w/o/w 型エマルションに塩 酸エピルビシンを封入し, 小型透析セルを用いた 溶出試験の結果を図 3 に示す。この溶出試験の結 果より, 薬物を封入してもっとも安定であったの は, 処方番号 1 の水相に HCO-60, 油相に HCO10 とCO-3の等量混合物を用いて調製したエマ ルションであると判断された，また，処方 4 の工 マルションは, 薬物溶液とほほ同様の溶出挙動を 示した.

各薬物封入エマルションを顥微鏡で観察したと ころ, いずれの処方でも $\mathrm{w} / \mathrm{o} / \mathrm{w}$ 型エマルション の調製を確認できたが，処方 4 のエマルションは

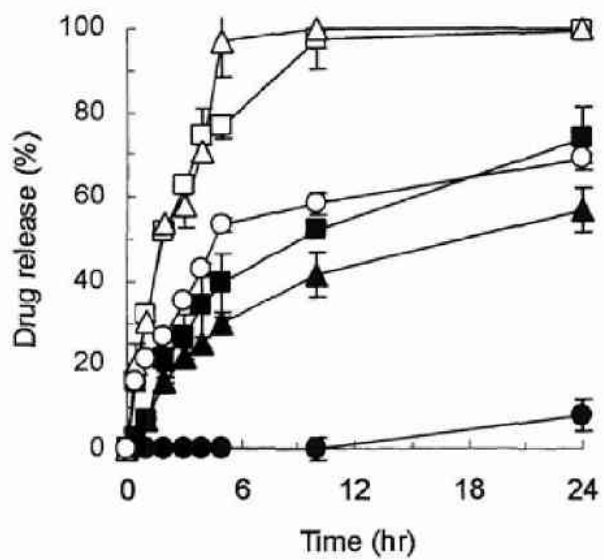

図 4 Effect of the type of drug formulated on the stability of MCT $\mathrm{w} / \mathrm{o} / \mathrm{w}$ emulsion (mean $\pm \mathrm{SD}, \mathrm{n}=3$ )

Model drug: Epirubicin hydrochloride(EPI), Doxorubicin hydrochloride(DOX), Evans blue (EB)

Conc. of drug in inner aqueous phase $: 5 \mathrm{mg} / \mathrm{ml}$

- Rp 1(EPI), - $\square-$ EPI solution, $-\mathbf{A p} 1$ (DOX), $\triangle-\mathrm{DOX}$ solution, - Rp 1(EB), $\rightarrow-$ EB solution

調製後, ただちにエマルションが破壊されて o/w 型エマルションヘと転相していくのが観察され た. また，溶出試験後のセル内のエマルションを 観察したところ, 処方 1,3 のエマルションはw/ o/W 型を保持していたが, 処方 4 のエマルション は完全に o/w型に転相していた. 図 3 の結果とこ れらの結果を考え合わせると，本小型透析セルを 用いた溶出試驗より得られる薬物の溶出挙動は, エマルションの安定性評価の指標として適したも のといえる。なお, 用いる界面活性凧の種類によ り薬物封入後のエマルションの安定性が異なった のは, エマルションの油滴表面に形成される界面 活性剂の会合構造の差に起因しており，HCO-10 と $\mathrm{CO}-3$ の混合物がもっともリジッドな構造を形 成しているものと推定される.

薬物に内封する薬物がエマルションの安定性に 及ぽす影響を検討するために, 塩酸エピルビシン と同様に TAEに繁用されている塩酸ドキソルビ シン $(\mathrm{DOX})$, およびエマルションの水溶性マー カーとしてよく用いられるエバンスブルー(EB) を用いて同様な評価を行った。 エマルションとし 

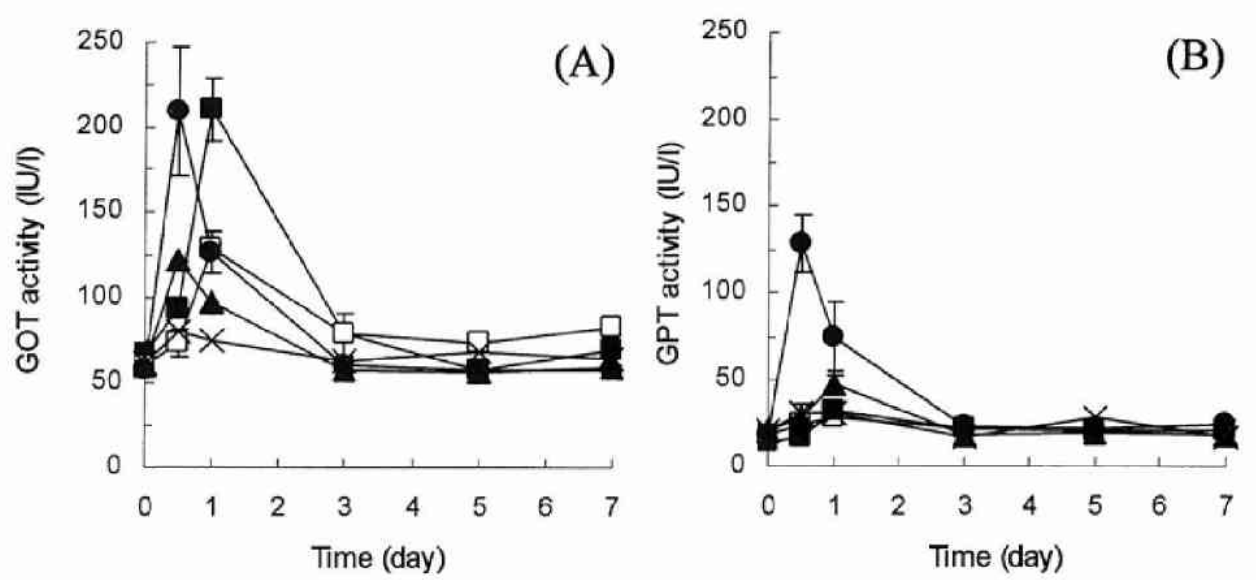

图 5 Plasma GOT and GPT levels after hepatic arterial injection of EPI loaded w/o/w emulsion or EPI solution

(A) Plasma GOT level, (B) Plasma GPT level(mean \pm SE)

- - $\square-\mathrm{MCT}$ w/o/w emulsion $(\mathrm{n}=3),-\mathrm{LPD}$ w/o/w $(\mathrm{n}=3),-\mathrm{LPD}$ o/w $(\mathrm{n}=3)$, $*$ EPI solution $(\mathrm{n}=1)$

closed symbols : EPI loaded, open symbol : no drug

ては処方 1 を用いた. 図 4 に示すように,いずれの モデル薬物も EPI 同様, エマルションに封入する ことにより透析セルからの溶出は顕著に抑制さ れ，徐放化が達成できることが示された。 また， 同一のエマルション処方を用いても，内封する薬 物によりその安定性は大きく変化することも示唆 された。

\section{(3) ラット正常肝への影響}

血中 GOT (glutamic oxaloacetic transaminase) 值は心筋梗塞, 劇症肝炎などで顕著に上 昇し, GPT (glutamic pyruvic transaminase) 值 は急性肝炎，慢性肝炎などで上昇する，それゆえ $に$ にこれらの生化学的検查值は, 肝疾患の治療上 の有力な指標として用いられている。そこで、エ マルションの肝動脈投与後, 肝機能の指標となる 血中 GOT, GPT 值のモニタリングを行い, 肝臓 への影響を評価した. 結果を図 5 に示す.MCT w/ o/w 型エマルションは, 現在臨床で繁用されてい るリピオト゚ール o/w 型エマルション投与群およ び当研究室でこれまでに開発したリピオドール w/o/w 型エマルション投与群と同様に, GOT レ ベルの一過的な上昇が観察されたが，3日以内に その值は正常レベルに戻った.GPTレベルにおい ては,リピオドール o/w 型エマルションにみられ
るような顕著な上昇は観察されなかった。これら の結果は, 油滴が微小循環を塞栓し, 肝細胞が虚 血壊死を起こしたためと考えられる.ゆえに MCT w/o/w 型エマルションは毒性が低く, TAE に用いる塞栓物質として適するものであるといえ る.

\section{(4) 肝臟内薬物滞留性}

肝動脈投与後の薬物の滞留性を比較検討するた めに, w/o/w 型エマルション, 薬物溶液を肝動脈 投与したあとの血中薬物瀼度の経時的変化を検討 した. 図 6 に示すように, 薬物溶液投与群において は初期に高い血中薬物濃度を示し, 肝㖑内に投与 された薬物が速やかに流出していることが示唆さ れた. w/o/w 型エマルション投与群においては, 初期における薬物の血中濃度の上昇は観察され ず, 薬物をエマルションに封入して投与すること で肝臓内の薬物の滞留性が向上することが示唆さ れた.

そこで, 実際の肝蔵内薬物濃度を測定した. 図7 に示すように, 正常肝においては薬物溶液投与群 と w/o/w エマルション投与群の間において有意 な差は認められなかったが, 腫湟肝においては投 与後 1 時間において有意な差が認められた。この

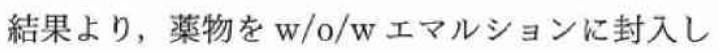



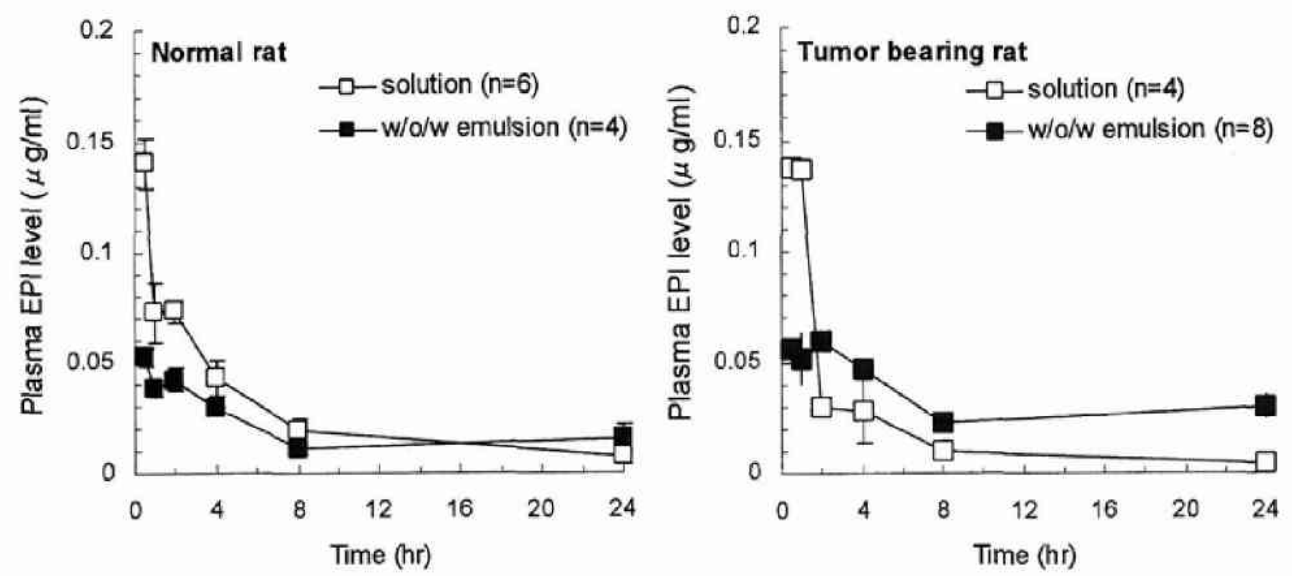

図 6 Concentration of EPI in plasma of normal rat(left) and tumor bearing rat(right) after hepatic arterial injection of EPI loaded in $\mathrm{w} / \mathrm{o} / \mathrm{w}$ emulsion or in a solution (mean \pm SE)
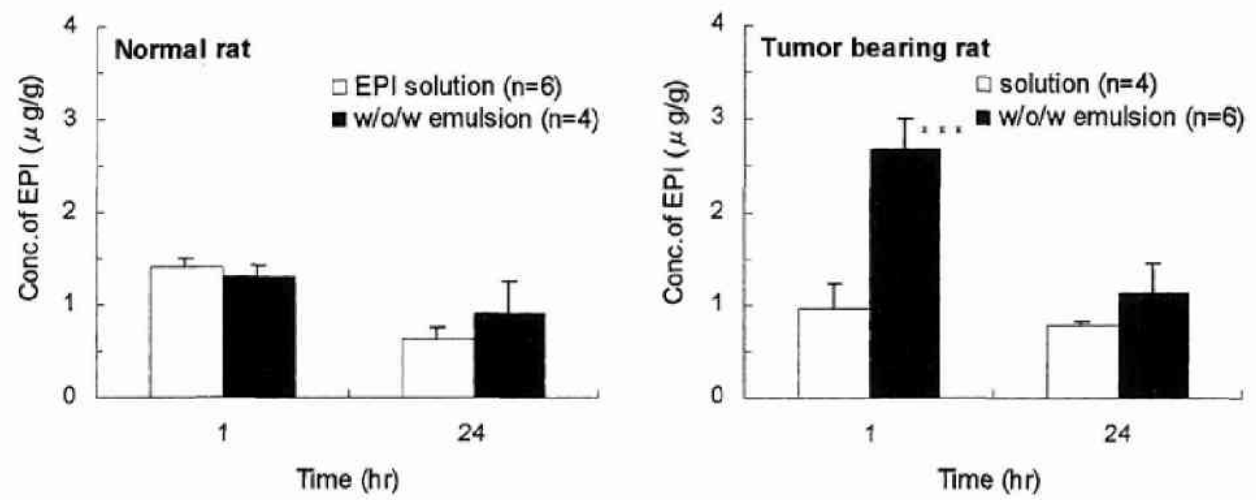

図 7 Concentration of EPI in liver of normal rat(left) and tumor bearing rat(right) after hepatic arterial injection of EPI loaded in $\mathrm{w} / \mathrm{o} / \mathrm{w}$ emulsion or in a solution $($ mean $\pm \mathrm{SE})$

て肝動脈投与することで, 薬物の肝葴内滞留性は 向上すると推定された.

肝動脈に投与された w/o/w 型エマルションは 肝動脈を塞栓し，動脈から腫瘍内に流れ込む血液 を遮断すると同時に, 封入された薬物を徐々に放 出すると考えられる.これらの結果より, 正常肝 よりも腫瘍肝において MCT w/o/w 型エマル ションは塞栓効果がすぐれていると考えられる. 腫瘍肝においては微細な新生血管が発達している うえ,リンパ系が末発達であるため", 腫場部位に エマルションの油滴が沈着し, 一部のエマルショ ンのみが徐々に正常肝組織の類洞へ流出したた
め,このような結果となったと推定される.また, 粒径 $10 \mu \mathrm{m}$ 程度の微細な粒子の場合は, 肝動脈投 与後, 速やかに肝内から逸脱することも報告され ている ${ }^{10,11)}$. 今回の投与法では, 血液にのせて間接 的に肝動脈内へエマルションを投与しているた め, 投与時にある程度エマルションが破壊され, 肝内より速やかに逸脱していることも考えられ る.よって正常組織と腫瘍組織の血流量の違いな ども寄与していることが推測される.

\section{結 論}

筆者らは，油相に MCT を用いても，二段階パ 
ンピング法により調製する安定な塩酸エピルビシ ン封入 $\mathrm{w} / \mathrm{o} / \mathrm{w}$ 型エマルションの処方を確立する ことができた. 同時に, 小型透析セルを用いた溶 出試験が安定性の評価に有用であることも明らか にした.

この $\mathrm{MCT} \mathrm{w} / \mathrm{o} / \mathrm{w}$ 型エマルションは, 肝動脈投 与時の毒性が低いことを GOT およびGPT 值の 測定により示した。また，腫瘍肝において EPI を w/o/w 型エマルションに封入することにより, 肝 動脈投与後の楽物の肝臓内滞留性を増大させ得る ことが示唆された。

本研究全般にわたってご協力いただきました， 磯崎正季子修士に感謝致します。

\section{文 献}

1) 本問久登, 新津洋司郎: 肝細胞の治療体系. CUR RENT THERAPY $16: 139-144,1998$.

2）日野知証, 竹内洋文, 丹羽敏幸, 長屋和正, 川島嘉明他 : 肝紐胞癌の塞栓療法のための塩酸エピルビシン封 スリピオドールエマルションの設計. DDS 10:115$119,1995$.

3）碡崎正季子, 日野知証, 山本浩充, 竹内洋文, 川島嘉 明・他：肝細胞癌の塞栓療法のための抗癌刘封入 $w /$ $\mathrm{o} / \mathrm{w}$ 型エマルションの設計と in vivo 評価. 日本薬学
会第 117 年会講演要旨集 $\quad(4): 213,1997$.

4）日野知証, 破崎正季子, 山本浩充, 竹内洋文, 長尾和 正・他：肝紐胞癌の塞栓療法のための塩酸エピルビシ ン封入 $\mathrm{w} / \mathrm{o} / \mathrm{w}$ 型エマルションのラットに対する急性 毒性の評価. DDS $10: 161-165,1997$.

5）柳本昌子, 丸山路之, 上沜権兵衛, 山上育恵, 椙田 実· 他：肝動脈に注入したりピオドールによる脳動脈塞栓 症の一例. 日救急医会誌 $4: 573,1993$.

6) リビオドールウルトラフルイド・医薬品インター ピューフォーム, 1996.

7) 柳井蕢雄：学位論文, 1997 .

8) Yanai S, Okada H, Misaki M, Saito K, Kuge Y et al. : Antitumor activity of a medium-chain trig. lyceride solution of the angiogenesis inhibitor TNP-470 (AGM-1470) when administered via the hepatic artery to rats bearing walker $256 \mathrm{car}$ cinoma in the liver. The American Society for Pharmacology and Experimental Therapeutics JPET 271: 1267-1273, 1994.

9) 前田 浩, 今野陖充, 岩井 穎, 牧 祥二郎, 田代征 記：油性造影剂(SMANCS/LIPIODOL) 動注による 腄湯の選択的攻撃.癌と化学療法 $11: 814-826,1984$.

10）塩月裕範, 末田秀人, 東 秀文, 瀬戸口敏明, 消水正 高・他：家鬼の固有肝動脈より投与されたりピオドー ル粒子サイスがリピオドールの肺内沈着に及涩す影 響。宮崎県工業試験場 平成九年度地域産業学官共同 研究事業研究報告書 : 39-42, 1998 .

11）塩月裕範，末田秀人，東 秀文，瀬戸口敏明，清水正 高・他：動注療法にっける肝癌治療の効果発現に及ほ すリピオドール粒子サイスの影響，宮崎県工業試験場 平成九年度地域産業学官共同研究事業研究報告書： $45-48,1998$. 